\title{
Implicações do software livre no ensino e aprendizagem: um estudo de caso no ensino médio politécnico
}

\author{
Alexsander Vasconcelos Canez ${ }^{1}$, Carlos Emilio Padilla Severo ${ }^{2}$ \\ ${ }^{1}$ Universidade Aberta do Brasil/IFSul - Instituto Federal Sul-rio-grandense - Praça \\ Vinte de Setembro, 455 - 96.015-360 - Pelotas - RS \\ ${ }^{2}$ Departamento de Ensino, Pesquisa e Extensão (DEPEX) - Instituto Federal Sul-rio- \\ grandense (IFSul) - Av. Leonel de Moura Brizola, 2501 - 96.418-400 - Bagé - RS \\ alex.avc@hotmail.com, carlossevero@ifsul.edu.br
}

\begin{abstract}
This paper describes an investigation about the adoption of free software as an educational resource in the teaching and learning process. For this, a research was conducted based on a case study in order to analyze the educational effects of an educational practice supported by technology. The problem has arise from the perception of the teacher about the difficulty of the students in use of applications such as supporting learning tools. The investigation of a qualitative nature was validated using data from direct and participatory observation of the teacher. The results were positive and meaningful. Therefore, it was possible to identify the performance and the implications of open source technologies as pedagogical resources in the school context.
\end{abstract}

Resumo. Este artigo descreve uma investigação sobre a adoção do software livre como recurso pedagógico no processo ensino e aprendizagem. Para isso, foi realizada uma pesquisa baseada em um estudo de caso, visando analisar os efeitos pedagógicos de uma prática educativa apoiada por tecnologia. A problemática surgiu a partir da percepção do professor acerca da dificuldade dos alunos no uso de aplicativos como ferramentas de apoio a aprendizagem. A investigação de natureza qualitativa foi validada a partir de dados provenientes da observação direta e participativa do professor. Os resultados foram positivos e significativos. Portanto, foi possível identificar o desempenho e as implicações de tecnologias de software livre como recursos pedagógicos no contexto escolar.

\section{Introdução}

A escola tem a função de formar cidadãos, dar aos alunos os ensinamentos de que eles necessitam para viver e trabalhar neste mundo de evolução, bem como orientá-los para a vida. Para auxiliar nessa formação muitos recursos podem ser agregados na prática pedagógica, tais como: livro didático, Internet, softwares de computador, revistas em geral, rádio, etc. Porém, segundo Prado (2005, p. 9) para obtenção de sucesso na integração de mídias no processo educativo, deve ser necessário conhecer as 
especificidades dos recursos midiáticos, de maneira que possa enriquecer com novos significados as situações de aprendizagem vivenciadas pelos alunos. Dessa forma, o professor deve ter conhecimento prévio sobre os recursos e os conteúdos a serem apresentados, pois torna-se difícil para o aluno discernir acerca de tantos recursos e conteúdos disponibilizados. Sendo assim, para que a mediação pedagógica seja realizada, Prado (2005) comenta que,

“[...] o professor precisa acompanhar o processo de aprendizagem do aluno, ou seja, entender seu caminho, seu universo cognitivo e afetivo, bem como sua cultura, história e contexto de vida. Além disso, é fundamental que o professor tenha clareza da sua intencionalidade pedagógica para saber intervir no processo de aprendizagem do aluno, garantindo que os conceitos utilizados, intuitivamente ou não, na realização do projeto sejam compreendidos, sistematizados e formalizados pelo aluno". [PRADO, 2005, p. 13].

Ao concluírem o ensino fundamental muitos estudantes têm dificuldades para realizar pesquisas e trabalhos escolares. Diversos problemas podem ser observados em muitos trabalhos escolares, pois é um "copia e cola” desenfreado, sem formatação correta, com assuntos que acabam fugindo da proposta apresentada pelo professor. Desse modo, faz-se necessário a aplicação de iniciativas para tentar contornar e compreender algumas dificuldades encontradas quando os alunos chegam ao primeiro ano do ensino médio.

Neste sentido, levantamos algumas questões que instigaram a problemática investigada nesta pesquisa, são elas: Como a Informática pode atuar como ferramenta pedagógica e auxiliar no ensino e aprendizagem? De que forma a fluência na escrita pode ser estimulada com o uso de software do tipo editor de texto? Como o uso da apresentação de slides pode auxiliar na expressão e estruturação do raciocínio do estudante? Como a combinação da Informática com mídias impressas podem contribuir no desenvolvimento da autonomia do estudante?

Portanto, neste texto descrevemos a metodologia empregada na prática educativa. Bem como, os resultados da convergência de duas mídias distintas no processo educativo. Dessa forma, apresentamos as percepções acerca das contribuições do software livre e atividades de leitura e pesquisa em revistas no âmbito educacional.

Além disso, com a aplicação da prática pedagógica, foi possível apresentar novos valores aos alunos, visto que tiveram a possibilidade de compreender e utilizar as potencialidades da mídia informática e mídia impressa em favor de seu aprendizado. Assim, o espaço educativo foi ampliado de modo a auxiliar na construção do raciocínio, criticidade e autonomia do estudante.

\section{Ensino politécnico e contribuições do Software Livre na educação}

Em 2011, o Rio Grande do Sul passou por uma reestruturação no ensino, que teve como ideia básica colocar o ensino médio para além da mera continuidade do ensino fundamental. Sendo uma etapa final da educação básica que surgiu com o escopo de preparar o aluno para o ensino superior e para o mercado de trabalho. Além de garantir o desenvolvimento dos alunos assegurando-lhes a orientação indispensável na formação cidadã. Então, a partir dessa ideia criou-se o chamado ensino nédio politécnico. 
De acordo com a Secretaria de Educação do Rio Grande do Sul (2011), essa mudança visa vários objetivos, tais como, relacionar a teoria com a prática por meio de seminário integrado, de modo a propiciar o desenvolvimento, qualificação, autonomia intelectual e pensamento crítico dos estudantes. Bem como, integrar as disciplinas de acordo com as quatro diferentes áreas do conhecimento (Ciências Humanas, Ciências da Natureza, Linguagens e Matemática e suas Tecnologias). Onde cada uma dessas áreas realiza avaliações pertinentes. Além disso, com o seminário integrado os alunos têm oportunidade de realizar atividades de pesquisa colocando em prática os fundamentos teóricos. Dessa forma, a proposta do ensino médio politécnico basicamente: "tem em sua concepção a base na dimensão politécnica, constituindo-se no aprofundamento da articulação das áreas de conhecimentos e suas tecnologias, com os eixos Cultura, Ciência, Tecnologia e Trabalho, na perspectiva de que a apropriação e a construção de conhecimento embasam e promovem a inserção social da cidadania". [Secretaria de Educação do Rio Grande do Sul, 2011, p. 10].

$\mathrm{Na}$ Educação, as novas tecnologias são vistas como ferramentas que servem para otimizar a prática pedagógica, proporcionando aulas mais dinâmicas e mais interessantes, onde são criados novos espaços que vão além da sala de aula. Saber utilizar essas tecnologias em prol do processo de ensino e aprendizagem é fundamental para o sucesso, visto que são muitos os recursos que podem ser utilizados como material didático. Uma vez que qualquer aparato tecnológico ou mídia pode ser considerado uma ferramenta pedagógica ou material didático, seja uma caneta, um livro, um computador, uma folha de ofício, etc. A diferença está no fato de que cada uma tem sua aplicação e finalidade, e, se utilizados corretamente, podem ser empregados para incrementar a prática pedagógica docente.

Dessa forma, são muitos os recursos que podem ser inseridos na prática pedagógica, porém de nada adianta a introdução de determinada tecnologia ou mídia em sala de aula se não for explorada de forma adequada, extraindo suas potencialidades e criando situações reais de aprendizagem. Neste contexto, para Caldas (2006), utilizar a mídia na escola é,

“[...] o primeiro passo para a leitura do mundo. Em contrapartida, é essencial que o exercício cotidiano no uso da mídia na sala de aula não se limite à leitura de jornais, revistas ou dos veículos eletrônicos. Para se ler o mundo a partir dos olhares dos outros, é fundamental que seus leitores aprendam antes a ler o mundo em que vivem, por meio da construção de suas próprias narrativas. Só assim será possível a construção do conhecimento, a transformação do educando em sujeito de sua própria história. A aquisição do pensamento crítico é resultado da inserção e percepção direta do aluno como agente mobilizador na sua realidade". [CALDAS, 2006, p.129].

A necessidade da inserção das mídias no processo de ensino e aprendizagem torna-se cada vez mais evidente. Contudo deve-se ter muita cautela, pois com a grande quantidade de recursos e conteúdos midiáticos que são inseridos na sociedade, existe grande possibilidade de utilizá-los de maneira inadequada. Logo, é extremamente necessário que as informações provindas das mídias sejam absorvidas de maneira inteligente e consciente, a fim de despertar no ser humano um raciocínio crítico e 
autônomo. Desse modo, destaca-se a importância da mediação e orientação do professor como métrica para que os alunos possam estruturar ou reestruturar suas ideias com base no fundamento teórico para utilizar tais recursos adequadamente [TERUYA e MORAES, 2009].

Outro ponto a ser considerado refere-se à disponibilidade de materiais para leitura e/ou escrita em meio eletrônico, que podem dar ao processo de ensino e aprendizagem uma outra realidade em que computador e a Internet estão reintroduzindo e reinventando a maneira de ensinar e aprender. Novas linguagens estão sendo criadas, tais como blogs, redes sociais (exemplo: Facebook e Whatsapp) e novas expressões e abreviações estão sendo incorporadas à linguagem (por exemplo: vc $=$ você, $\mathrm{t}+=$ até mais). As mudanças que essas tecnologias causam no ambiente escolar são evidentes. Porém, segundo Kenski (2003, p. 233) "O ambiente digital não substitui as formas orais e impressas com as quais tradicionalmente os professores ensinam", em outras palavras, ele não pode substituir e sim incrementar e (re)significar a prática pedagógica do educador.

Segundo a definição criada pela Free Software Foundation, software livre "é qualquer programa de computador que pode ser usado, copiado, estudado, modificado e redistribuído com algumas restrições". A liberdade em manusear suas diretrizes se opõe ao conceito de software proprietário, mas não ao software que é vendido (software comercial), ou seja, isso quer dizer que o software livre não necessariamente seja gratuito, logo em muitos casos ele é pago. Então, a maneira usual de distribuição de software livre é anexar a este uma licença de software livre, e tornar o código fonte do programa disponível [CÁRGANO, 2012].

A inserção do software livre na educação representa um importante reforço para o aprendizado dos estudantes, pois inserir o computador e o software livre na educação cria condições e motivação para aprender e para que os estudantes possam construir um novo enredo para suas vidas [FERNANDES, 2011, p. 4]. O software livre contribui para o aprendizado em diversos aspectos, pois estimula o estudante aprender a resolver problemas do seu dia a dia que serão importantes em sua futura trajetória profissional. $\mathrm{O}$ computador visto como recurso pedagógico pode despertar o interesse na construção de saberes e aprendizagens, além de favorecer a diversificação das formas de representação e do uso da linguagem.

Fernandes (2011) destaca a importância e a mudança em sala de aula que são proporcionadas por meio do computador com o software livre Linux Educacional. O estudo concluiu que o uso do software livre e seus aplicativos na prática pedagógica possibilitam ao professor a criação e a aplicação de recursos pedagógicos digitais no processo de ensino e aprendizagem. Ainda, destaca que essa importante ferramenta contribui para a inclusão digital, social e os letramentos múltiplos de professores e estudantes. Os resultados e conclusões motivaram a autora a continuar investigando e utilizando outros materiais pedagógicos digitais e tutoriais dos aplicativos de software livre.

Flores (2013) propôs uma experiência que utiliza planilha eletrônica nas aulas de matemática. O estudo foi aplicado em uma turma de sexta série de uma Escola Estadual de Ensino Fundamental do Rio Grande do Sul em 2010. A proposta tem como principal 
objetivo desenvolver a aprendizagem por meio da construção de conceitos matemáticos utilizando planilha eletrônica. Esta possibilitou aos estudantes utilizarem o software para dinamizar a aula e assim oferecer um recurso onde os problemas matemáticos puderam ser testados e simulados. Para realizar as tarefas foi utilizada a planilha eletrônica Calc do LibreOffice. Pelo estudo, foi possível observar resultados significativos no processo de ensino e aprendizagem [FLORES, 2013, p. 204], visto que proporcionou o desenvolvimento da autonomia, coletividade e construção do conhecimento matemático.

Outro estudo que utilizou o Calc foi apresentado no artigo de Bastos e Marcello (2014), porém este foi aplicado no ensino de Física para alunos do ensino médio do Instituto Federal do Amapá em 2013. O trabalho propôs o desenvolvimento de atividades de modelagem matemática relacionadas aos conteúdos com maior dificuldade para os estudantes, visando associar e correlacionar a teoria com a prática.

O estudo de Melo, Moreira e Silva (2014) descreve uma pesquisa de campo sobre a fluência dos professores na inserção do LibreOffice nas práticas pedagógicas. Comenta que editores de texto como o Writer "ajudam no desenvolvimento das habilidades linguísticas. Com eles é possível elaborar atividades de criação de relatórios, cartas poesias, músicas, entrevistas, caça-palavras, palavras cruzadas, cartões, livros e jornais. A criatividade depende do professor".

Também mostrou que a maioria dos professores não são fluentes na utilização do LibreOffice em suas práticas pedagógicas, principalmente pelo fato de a maioria nunca ter participado de algum tipo de formação sobre o assunto. $\mathrm{O}$ que evidencia a necessidade da formação continuada, visando a atualização e o aperfeiçoamento dos professores de modo a enriquecer o processo de ensino e aprendizagem.

\section{Metodologia de pesquisa}

A pesquisa teve um caráter qualitativo, com base em um estudo de caso envolvendo uma prática educativa com tecnologias da Informática. Os instrumentos de coleta de dados foram a observação direta e participativa do professor responsável pela disciplina durante o processo de mediação da aprendizagem junto aos estudantes; e, um questionário diagnóstico que possibilitou coletar e identificar alguns pontos relevantes e conhecimentos prévios dos alunos acerca do tema.

A prática educativa foi realizada em uma turma com 19 alunos do $1^{\circ}$ ano do ensino médio politécnico da Escola Estadual de Ensino Médio Arroio do Padre, no município de Arroio do Padre - RS, no ano de 2015. Para delimitação do tema a ser abordado na prática educativa, foi realizado um levantamento prévio acerca das dificuldades encontradas pelos docentes da escola durante sua prática pedagógica. Assim, constatou-se que muitos estudantes possuíam sérias dificuldades na realização de pesquisas e trabalhos escolares. Principalmente, tratando-se da utilização da mídia Informática como ferramenta para produção e organização textual. Dessa forma, propomos um trabalho investigativo visando realizar um estudo das implicações do emprego de ferramentas de software livre no processo de ensino e aprendizagem.

Para auxiliar nesse processo foram utilizadas duas mídias convergentes como ferramentas pedagógicas: 
V Congresso Brasileiro de Informática na Educação (CBIE 2016)

Anais do XXII Workshop de Informática na Escola (WIE 2016)

- a mídia impressa, na forma de revistas que abordem temas de interesse educacional e relacionados com as disciplinas abordadas na turma;

- e a mídia da Informática, na forma de aplicativos do pacote LibreOffice, tais como o Writer (editor de textos) e o Impress (programa para criação de apresentações na forma de slides).

Sendo assim, foi apresentada uma proposta pedagógica visando verificar as implicações das mídias citadas no processo de ensino e aprendizagem. Bem como, levantar algumas abordagens didáticas que podem ser implementadas pelo professor em sua proposta pedagógica. Portanto, algumas ações foram tomadas.

Em um primeiro momento foi realizada uma revisão bibliográfica, que envolveu alguns trabalhos relacionados com o tema da pesquisa, e, possibilitou conhecer e compreender alguns pontos relevantes. Além de proporcionar uma contextualização da pesquisa e uma fundamentação para a prática pedagógica proposta.

Em um segundo momento foi aplicado um questionário fechado com 16 questões de múltipla escolha. O objetivo do questionário foi uma avaliação diagnóstica, verificando-se o conhecimento prévio dos estudantes acerca do tema, onde foram constatadas algumas dificuldades acerca da problemática apresentada.

Em seguida, partiu-se para um estudo de caso e iniciou-se a aplicação da prática educativa junto aos estudantes da disciplina de seminário integrado. A prática educativa iniciou com a apresentação dos objetivos aos estudantes. Em seguida, houve a ambientação que possibilitou aos alunos a familiarização com as ferramentas propostas. Após, o professor selecionou alguns temas em revistas que foram distribuídas aos alunos para escolherem algum assunto entre os selecionados. Por fim, os estudantes elaboraram um relatório de texto no Writer e uma apresentação de slides no Impress sobre o tema proposto pelo professor e escolhido por eles. Então, suas produções foram apresentadas para o professor e os demais colegas de turma.

Posteriormente, em posse dos dados observados foi realizada uma análise e descrição da prática educativa envolvendo a tecnologia utilizada, visando entender e interpretar os aspectos relevantes para responder a problemática apresentada. Através da análise dos resultados procurou-se identificar o desempenho e as implicações do uso das mídias utilizadas no processo de ensino e aprendizagem, tal como, de que maneira a inserção dessas mídias podem contribuir e influenciar no contexto escolar.

\section{Análise dos resultados}

Quando ficaram sabendo sobre a proposta educativa alguns estudantes demonstraram um certo receio em relação as mídias que seriam utilizadas. Contudo, após a explicação de como seria desenvolvida a prática, eles foram mudando de opinião e ficaram mais motivados. Pois, perceberam a possibilidade de aprenderem algo novo e que ainda poderia ser introduzido como mais uma possibilidade no desenvolvimento de suas aprendizagens.

A faixa etária dos alunos varia entre 15 e 18 anos, com exceção de um aluno com 66 anos de idade, sendo a grande maioria proveniente do EJA (Educação de Jovens e Adultos) do ensino fundamental. Destes, 66,7\% utilizam o Windows em seus computadores e o restante não possui computador em casa, em contrapartida nenhum 
dos alunos tem o Linux ou outro Sistema Operacional instalado em seus computadores. Eles também não sabiam o que é um software livre e muito menos como utilizar o Writer e o Impress. Logo, comprometeu em partes o prazo da prática educativa, pois por ser algo novo a curva de aprendizado dos alunos foi maior.

Em torno de $30 \%$ dos alunos não sabiam utilizar nenhum tipo de software para editar apresentação de slides. Dos alunos que sabiam apenas 50\% usava slides (sabiam usar somente o PowerPoint) em suas apresentações e os demais não apresentavam seus trabalhos com slides.

Também foi questionado sobre o sentimento dos alunos quando apresentavam seus trabalhos, sendo que $77,8 \%$ tinham medo ou vergonha e $22,2 \%$ não tinham nenhum problema em apresentar suas produções ao restante da turma e ao professor. Durante a realização da pesquisa percebeu-se que os alunos foram se soltando um pouco mais e, em alguns, esses receios foram diminuindo. Eles começaram a sentir mais confiança pois já sabiam manipular o software para construir sua própria apresentação. A partir daí constatou-se como a apresentação de slides pode auxiliar na expressão em sala de aula e na construção do raciocínio do estudante.

Em relação ao editor de textos, $72 \%$ dos alunos informou que tinha algum tipo de dificuldade em utilizar e nenhum deles sabia usar o Writer, pois conheciam apenas o Word. Percebeu-se que conforme os alunos foram aprendendo a utilizar o Writer, houve a possibilidade de melhora na gramática e ampliação do vocabulário. Porém serão necessárias mais aulas para comprovar essa expectativa.

Quanto ao uso de mídia impressa para estudar, constatou-se que a grande maioria $(72,2 \%)$ utilizava livros e/ou revistas para auxiliar em seu aprendizado. Porém, apenas $44,4 \%$ informou que estes recursos ajudavam de maneira significativa. Um método que foi utilizado para contornar esse problema ou reforçar a importância da mídia impressa no aprendizado, se deu pela possibilidade de os alunos poderem escolher um dos temas selecionados pelo professor, pois isso os deixou mais confiantes já que de certo modo puderam escolher o assunto que iam estudar dentre os que estavam disponíveis. Dessa forma, constatou-se uma melhoria no processo de ensino e aprendizagem, pois os alunos se mostraram mais motivados, onde puderam construir suas produções a partir de um artigo em revista, e com uma nova ferramenta (mídia informática) que desconheciam.

Apesar de resultados positivos e satisfatórios, foram observados alguns problemas durante a aplicação do estudo de caso. Ao final da pesquisa constatou-se que seriam necessárias mais horas/aula para atingir resultados ainda mais significativos, pois devido ao fato de que os alunos não tinham conhecimento prévio sobre a mídia informática utilizada, o tempo de aplicação da pesquisa não foi suficiente. Outro agravante se deu pela falta de computadores no Laboratório de Informática da escola, pois dos 20 que existiam apenas 8 estavam funcionando, logo muitos alunos tiveram que compartilhar um mesmo computador.

\section{Considerações finais}

Para finalizar, realizaremos algumas reflexões conclusivas acerca do trabalho. Dessa forma, constatou-se a fragilidade dos estudantes ao concluírem o ensino fundamental, 
tratando-se do uso das mídias em favor do ensino, seja para realizar pesquisas ou elaborar os trabalhos solicitados pelos professores. Sendo assim, verificamos a importância e a necessidade da aplicação de propostas pedagógicas que insiram diferentes tipos de mídias no contexto escolar.

Assim, buscou-se com os resultados do estudo de caso perceber as contribuições e as implicações do software livre e a pesquisa em revistas no âmbito educacional. Bem como, apresentar novos valores aos alunos de modo que pudessem compreender e soubessem utilizar as potencialidades da mídia informática e da mídia impressa em favor de seu aprendizado, ampliando o espaço educativo e auxiliando na construção do raciocínio, criticidade e autonomia do aluno.

Também foi feita uma revisão bibliográfica que possibilitou verificar alguns conceitos e experiências de outros estudos sobre temas relacionados ao apresentado neste artigo. Tal como conhecer e compreender alguns pontos relevantes, além de proporcionar uma contextualização da pesquisa e uma fundamentação teórica para a prática pedagógica aplicada.

Com este estudo constatou-se que o espaço pedagógico pode ser ampliado com a inserção das mídias como recursos pedagógicos, podendo haver um ganho considerável no processo de ensino aprendizagem. Entretanto, esse ganho pode se concretizar ao passo que as mídias forem utilizadas corretamente e com a orientação e mediação efetiva do professor, a fim de obter sucesso com sua proposta de ensino.

De modo geral os resultados obtidos foram positivos e significativos, visto que possibilitaram identificar o desempenho e as implicações das mídias como recursos pedagógicos inseridos no contexto escolar. Constatou-se uma melhoria no processo de ensino e aprendizagem, visto que os alunos se mostraram mais motivados e as aulas foram se tornando mais dinâmicas. Bem como, ficou constatado que as mídias proporcionam novos métodos de ensino com aulas mais atrativas e com maior participação ativa dos alunos nas aulas.

Um dos principais problemas enfrentados foi em relação ao número de computadores, pois eram 8 para 19 alunos, logo muitos tiveram que compartilhar um mesmo computador. Além disso, nenhum deles tinha conhecimento prévio sobre o Writer e o Impress, comprometendo em partes o tempo de aplicação do projeto, já que a curva de aprendizado dos alunos foi maior do que o esperado. Entretanto, ao final do projeto todos os computadores foram consertados, mas os alunos não tiveram oportunidade de usá-los.

Outro problema constatado foi a falta de uma pessoa qualificada para atuar como monitor no Laboratório de Informática, e, auxiliar no aprendizado da mídia informática, possibilitando aos alunos a oportunidade de familiarizar-se e aprender a usar os recursos disponíveis dessa mídia. Dessa forma, quando os professores desejarem aplicar algum projeto que envolva a mídia informática, os alunos já estarão maior familiaridade com as ferramentas disponíveis. Logo, destaca-se a importância da contratação de um monitor para atuar no laboratório.

Em conversa informal com outros professores da escola percebeu-se que diante das dificuldades dos alunos seria importante que o projeto fosse estendido para as 
demais turmas, pois as dificuldades constatadas também foram observadas no restante dos alunos. E que com esse tipo de projeto as atividades das aulas podem ser mais dinâmicas e os resultados esperados com as propostas de ensino provavelmente serão mais expressivos.

\section{Referências bibliográficas}

BASTOS, A. M.; MARCELLO, T. B. (2014) Ensino de Física utilizando LibreOffice Calc. $3^{\circ}$ Congresso Brasileiro de Informática na Educação (CBIE 2014), $20^{\circ}$ Workshop de Informática na Escola (WIE 2014), p. 165 - 169.

CALDAS, G. (2006) Mídia, escola e leitura crítica do mundo. Educ. Soc., Campinas, vol. 27, n. 94, p. 117-130.

CÁRGANO, F. B. (2012) A comunidade de software livre e de código aberto nas redes sociotécnicas. Dissertação (Mestrado em Sociologia) - Setor de Ciências Humanas, Letras e Artes, Universidade Federal do Paraná.

FERNANDES, J. H. M. (2011) Software livre na educação para além da inclusão digital e social: Letramentos Múltiplos de Professores e Alunos. Periódicos Texto Livre - UFMG, v. 4, n. 1.

FLORES, J. B. (2013) O uso de planilhas eletrônicas nas aulas de Matemática no ensino fundamental. Caderno de Estudos Tecnológicas, Faculdade de Tecnologia de Bauru - FATEC, v. 1, n. 1, p. 199 - 2007.

KENSKI, V. M. (2003) Ação docente e livro didático nos ambientes digitais. In: Nova, C. e Alves, L. Educação e Tecnologia: Trilhando Caminhos. Salvador: UNEB, p. $225-235$.

MELO, R. F.; MOREIRA, W. A.; SILVA. L. R. (2014) Utilização do pacote de escritório LibreOffice no auxílio da prática pedagógica no colégio estadual Osvaldo Franco. V Encontro Nacional das Licenciaturas.

PRADO, M. E. B. B. (2005) Integração de tecnologias com as mídias digitais. Salto para o futuro: integração de tecnologias, linguagens e representações. TV Escola, Ministério da Educação. Boletim 05.

MINISTÉRIO DA EDUCAÇÃO. (2005) Pedagogia de projetos: fundamentos e implicações. In: Almeida, M. E. B.; Moran, J. M. Integração das Tecnologias na Educação. Salto para o Futuro. TV Escola. Brasília: Secretaria de Educação a Distância - SEED. Ministério da Educação, p. 12 - 17.

SECRETARIA DE EDUCAÇÃO DO RIO GRANDE DO SUL. Proposta Pedagógica para o Ensino Médio Politécnico e Educação Profissional Integrada ao Ensino Médio - 2011- 2014.

TERUYA, T. K.; MORAES, R. A. (2009) Mídias na educação e formação docente. Linhas Críticas, Brasília, v. 14, n. 27, p. 327-343. 